OPEN ACCESS

Edited by:

Viviana Masia,

Sapienza University of Rome, Italy

Reviewed by:

Didier Maillat

Université de Fribourg, Switzerland

Diana Mazzarella,

Université de Neuchâtel, Switzerland

${ }^{*}$ Correspondence:

Edoardo Lombardi Vallauri edoardo.lombardivallauri@uniroma3.it

Specialty section:

This article was submitted to

Language Sciences,

a section of the journal

Frontiers in Communication

Received: 27 September 2020

Accepted: 26 February 2021

Published: 07 April 2021

Citation:

Lombardi Vallauri E (2021)

Manipulative Shallow Processing

Induced by Presuppositions and Topics: Theoretical Perspectives and

Experimental Evidence.

Front. Commun. 6:610807. doi: $10.3389 / f c o m m .2021 .610807$

\section{Manipulative Shallow Processing Induced by Presuppositions and Topics: Theoretical Perspectives and Experimental Evidence}

\author{
Edoardo Lombardi Vallauri* \\ Dipartimento di Lingue, Letterature e Culture Straniere, Università Roma Tre, Rome, Italy
}

The paper shows that implicit strategies for questionable contents are frequent in persuasive texts, as compared to texts with other purposes. It proposes that the persuasive and manipulative effectiveness of introducing questionable contents implicitly can be explained through established cognitive patterns, namely that what is felt by addressees as information coming (also) from them and not (only) from the source of the message is less likely to be challenged. These assumptions are verified by showing examples of "implicitness of evidential responsibility" (essentially, presuppositions, and topics) as triggers of lesser attention in advertising and propaganda. A possible evolutionary path is sketched for three different pragmatic functions of presuppositions, leading to their availability for manipulation. The distraction effect of presuppositions and topics is also explained in relation with recent developments of Relevance Theory. Behavioral evidence that presuppositions and topics induce low epistemic vigilance and shallow processing is compared to recent neurophysiological evidence which does not confirm this assumption, showing greater processing costs for presuppositions and topics as compared to assertions and foci. A proposal is put forward to reconcile these apparently contrasting data and to explain why they may not be in contrast after all. Also due to natural language quick processing constraints (a "Now-or-Never processing Bottleneck"), effort devoted to accommodation of presupposed or topicalized new contents may drain resources from concurrent epistemic vigilance and critical evaluation, resulting in shallower processing.

Keywords: persuasion and manipulation, evolved cognitive bias, presuppositions, topics, shallow processing, behavioral and neurophysiological evidence

\section{THE PRESENCE OF IMPLICIT STRATEGIES IN PERSUASIVE COMMUNICATION}

A wide range of recent and less recent studies (which we will refer to below) deal with the fact that implicit strategies, and backgrounded information in particular, are involved in persuasion. It has recently been shown that, together with topicalizations, presuppositions frequently introduce questionable contents in persuasive communication such as commercial advertising and political propaganda (Lombardi Vallauri, 2009b, 2016, 2019; Lombardi Vallauri and Masia, 2014, 2020). The paper will give examples of this fact, and will try to deal with some factors that may account for it. 
In this section we introduce the fact that implicit strategies are frequent in persuasive texts and perform persuasive functions. Section The Persuasive Effectiveness of Implicit Strategies: A Cognitive Approach tries to give a cognitive explanation for their persuasive and manipulative effectiveness. Section Implicitness of Evidential Responsibility as a Trigger of Lesser Attention shows examples of implicitness of evidential responsibility (essentially, presuppositions and topics) as triggers of lesser attention in advertising and propaganda. Section Multiple Functions of Presuppositions: Economic and Persuasive Reduction of Attention sketches a possible evolutionary path for three different pragmatic functions of presuppositions leading to their availability for manipulation. Section Presupposition Distraction and Relevance Theory adopts a closer look toward the distraction effect of presuppositions, by relating it to some recent developments of Relevance Theory. Section The Starting Hypothesis: The Brain Processes Differently What Language Presents Differently presents behavioral evidence that presuppositions and topics induce shallow processing, and neurophysiological evidence which does not confirm this assumption. Section Interpreting Disorder: We Don't Measure the Right Thing Yet tries to reconcile the apparently contrasting data and to explain why they may not be in contrast after all.

Commercial advertising and political propaganda should be particularly rich in persuasive strategies (including implicitness), given the prominent persuasive function of these kinds of messages. We will try to build more solid evidence in favor of this common sense intuition. Ads are made of very short texts, where it is difficult to assess the quantitative impact of given linguistic constructions and strategies, but it has been shown that in political discourse contents that are not bona fide true are more frequently conveyed by means of implicit strategies, as compared to other kinds of texts. By "implicit strategies" we mean not only the linguistic phenomena treated in the present paper (namely, presuppositions and topics), but also implicatures and vague expressions.

The method first proposed in Lombardi Vallauri and Masia (2014) allowed to measure the different amounts of doubtful contents introduced by means of linguistic implicit strategies in different speeches by different politicians. Other kinds of texts use implicit strategies to introduce questionable contents with frequencies that are even more different. As an example, we summarize here the results of a comparison between some Italian, American and French political speeches (all given in 2012) and texts of other kinds (from Lombardi Vallauri and Masia, 2014; Lombardi Vallauri, 2019, to which we refer $)^{1}$. The numerical scale adopted to express the amount of implicitness in

\footnotetext{
${ }^{1}$ The mentioned texts can be found here:

Enrico Letta: http://www.youtube.com/watch?v=uuQ3QaB8rII

Matteo Renzi: http://www.youtube.com/watch?v=DAM4rYp1o6w

Marine Le Pen: http://www.frontnational.com/videos/udt-2012-la-bauleintervention-de-marine-le-pen/

Ségolène Royal: http://blogs.mediapart.fr/blog/jean-marie-padovani/040412/ discours-de-segolene-royal-rennes

Rick Santorum: http://www.washingtonpost.com/blogs/election-2012/post/ rick-santorums-michigan-primary-speech-full-text-and-video/2012/02/28/ gIQAtFsJhR_blog.html
}

TABLE 1 | Impact of the implicit encoding of doubtful contents in different kinds of texts.

\begin{tabular}{lr}
\hline Erbolario promotional brochure & 23 \\
Speech by Marine Le Pen & 22 \\
Speech by Mitt Romney & 16 \\
Speech by Rick Santorum & 10 \\
Speech by Matteo Renzi & 10 \\
Speech by Ségolène Royal & 6 \\
Speech by Enrico Letta & 6 \\
Touristic description brochure-Scottish Castles & 5 \\
Package leaflet of a medicament & 1.7 \\
Introduction to Cambridge Examination Papers & 0.6
\end{tabular}

each text depends on parameters that don't need to be explained here, but what counts for our discourse are the relative values, i.e., the differences between the listed texts (Table 1).

As it can be seen, the difference in the frequency of implicit strategies conveying questionable information between two speeches of two different Italian politicians (in this case, Matteo Renzi and Enrico Letta) can reach 40\% (in the adopted measuring method-cf. Lombardi Vallauri and Masia, 2014-the conventional numerical value is 10 for Renzi vs. 6 for Letta). But they are both located near the middle of a scale where they are preceded (in decreasing order) by an advertising brochure and by political speeches by Marine Le Pen, Mitt Romney, and Rick Santorum. A speech by Ségolène Royal falls between the two Italian rivals, and they are all followed by an informative brochure about the Castles of Scotland, the package leaflet for a medicament and the Introduction to the Cambridge Examination Papers, where the implicitation of doubtful contents falls almost to zero. It must be stressed that-consistently with common sense expectations - the most dramatic reduction (considered in percentage) in the frequency of implicit strategies happens from persuasive texts (advertising and political propaganda) to texts with merely informative aims.

Such data are confirmed by a more extensive analysis done on a corpus of about 1 million characters, equally distributed among 8 kinds of texts (Lombardi Vallauri and Masia, 2020). Figure 1 shows the extension of linguistic material implicitly conveying doubtful contents in different portions of the corpus. For example, persuasive implicit constructions occupy $21 \%$ of the extension of political speeches in the corpus, and only $0.08 \%$ of university lessons.

We will now try to briefly sketch why implicitness can work to enhance persuasion.

Mitt Romney: http://www.washingtonpost.com/blogs/post-politics/post/ mitt-romneys florida-republican-primary-speech-full-text/2012/01/31/ gIQA8tYKgQ_blog.html

Erbolario: http://www.erbolario.com/filemanager/img/pdf/frutto-della-passione. pdf

Scottish Castles: http://www.visitscotland.com/about/history/castles/

Cambridge First Certificate in English 7: Examination Papers from University of Cambridge - ESOL Examinations, Cambridge University Press, 2005. 


\section{Extension of implicit strategies in different kinds of texts}

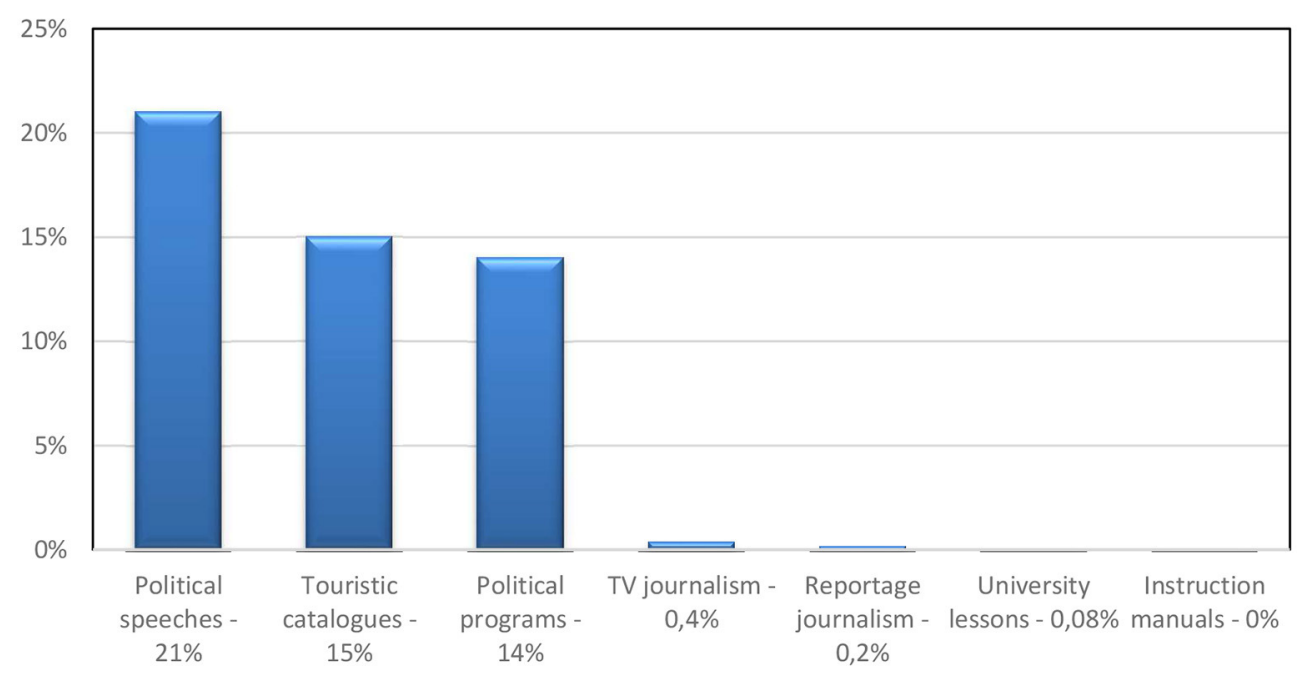

FIGURE 1 | Extension of implicit strategies for questionable contents in a corpus (data from Lombardi Vallauri and Masia, 2020).

\section{THE PERSUASIVE EFFECTIVENESS OF IMPLICIT STRATEGIES: A COGNITIVE APPROACH}

In advertising and other kinds of persuasive communication, textual elements are by far less important than images. This is due to the fact that the brain devotes more processing resources to vision than to language, but also to the fact that images convey contents in a not explicit way. In other words, images are effective because they do not make statements.

As observed in Lombardi Vallauri et al. (2020),

When, as in a famous and long-running commercial, you see a group of young, attractive, rich, and happy people drinking some whisky in a wonderful house, you will be, to a certain extent, influenced by the following idea: "If you want to look cool like them, you should drink that whisky." The same content, if stated explicitly, would rather provoke hostile reactions; but in its visual, "implicit," not-stated version it probably works; otherwise the ad would not have been proposed the same way for decades.

We can try to explain such effects. Krebs and Dawkins (1984, p. 383) suggested that not only cooperation, but also manipulation is an aim that guided the evolution of animal communication, i.e., the need to influence other individuals' behaviors. They further suggested that also the specular ability to resist manipulation must have evolved, namely the tendency to become aware and to resist the manipulator's attempts to trigger specific behaviors (390-392). This resistance is obviously based on the ability to detect the manipulator's intentions.

Krebs and Dawkins (1984) thus formulate the prediction that "interactions are likely to be characterized by coevolution between persuasion and sales-resistance" (p. 394, italics ours).
This is most likely to happen also in human communication. When we become aware that some conspecific tries to persuade us, we resist by checking their arguments and possibly rejecting them. In other words, linguistic communication, conceived among the other kinds of animal interaction, should obey the following rule:

Awareness that the source is trying to modify our beliefs increases the chances of critical reaction.

The form of communication that most overtly carries the intention to modify the addressee's beliefs is assertion. Statements-by definition-present themselves with a conspecific individual as their source, trying to make us believe that their content is true. With Krebs and Dawkins, we propose that the awareness that someone wants to modify our set of beliefs triggers our critical reaction (sales-resistance, in their terms) and our tendency to critically evaluate certain content. Processing a statement includes checking its truthfulness. Now, we propose that this tendency to critically evaluate the information we are exposed to is weaker when we feel that we are free to form our opinion autonomously, as it typically happens with images, where the presence of a conspecific individual trying to convince us is far less evident: although in present-day world images aimed at persuading us are built up by someone, this is a very recent state of affairs: during the overwhelming majority of our evolution time, images have always been real, not fabricated. As a consequence, we cannot have evolved the same instinctual "sales resistance" to images as to utterances. Of course we can become aware of some images' being fabricated if we devote specific attention to the matter, but when we just watch idly and do not focus on the origin of what we see, if Krebs and Dawkins are right, images will, for evolutionary reasons, trigger less suspicion and vigilance as compared to overt statements. 
As a consequence, assertion can work pretty well if one conveys strong and convincing arguments, but, in order to persuade through contents that-if critically evaluated-will prove wrong or exaggerated, assertion is a particularly unsuitable device. So, in persuasive communication, doubtful contents are preferably entrusted to images. This is what happens when, for example, an advertising clip portrays a very happy and good looking family in a very elegant house having breakfast with some brand of cornflakes: the message that to a certain extent passes into the target's minds is that there is a strong association between being that kind of people and eating those cornflakes. But the very same message would hardly convince anyone if overtly stated by means of an assertion: "Those who are happy and good looking and have very elegant houses have breakfast with our cornflakes!;” or, even worse: “Those who have breakfast with our cornflakes will end up being happy and good looking and having very elegant houses!.” In other words, images show some real-looking things but they do not state the meaning such things should be given. In this sense, a fair amount of their meaning is added (sometimes precisely inferred) by the target, exactly as it happens with (canonical) linguistic implicit content.

So, when some questionable content is such that it cannot be conveyed through images, and it needs to be encoded through language (for example because it is very specific or very abstract), then the linguistic form to be preferred is a non-assertive one. Languages provide users with implicit constructions, such as implicatures and presuppositions, which can prove a fair solution to this problem: several scholars have noticed that implicit strategies can be used to reduce addressees' critical attention (Ducrot, 1972; Givón, 1982; Kerbrat-Orecchioni, 1986; Rigotti, 1988; Lombardi Vallauri, 1993; and specifically for texts with persuasive aims Lombardi Vallauri, 1995, 2009b, 2016, 2019; Sbisà, 2007; Reboul, 2011, 2017; De Saussure, 2013; Lombardi Vallauri and Masia, 2014).

Reboul (2011, p. 10) suggests that "implicit communication evolved to facilitate manipulation by allowing communicators to hide their (manipulative) intentions." This happens because implicit strategies partly conceal the communicator's intention to persuade, thus "circumventing" critical judgment on their content. Mercier (2009, p. 117) contends that:

when someone tells us something and we accept it, and we draw inferences based on that information, we consider the resulting new conclusions as ours (Mercier, 2009, p. 117, translated).

Implicit contents are typically information that we feel as more arrived at by ourselves, as compared to contents explicitly proposed by the source of the message. As a consequence, inferred contents will be more easily accepted than those explicitly communicated by our interlocutor:

The less important the communicator's role in the formation of the conclusion by the addressee, the more the addressee will accept the conclusion (Mercier, 2009, p. 118, translated).
This cognitive limitation is often referred to as the "egocentric bias:"

The egocentric bias leads to a preference for one's own beliefs and will induce a preference for beliefs which one has reached by oneself; this explains why it may be advantageous for the communicator to use implicit communication: it allows him to induce in his addressee beliefs (i.e., reasons and conclusions) which the addressee having reached them by himself will be more prone to accept, and to hide his ultimate intentions regarding the conclusion he wants the addressee to reach as to the future course of her action (Reboul, 2011, p. 17).

Such tendencies are by no means restricted to language. Rather, they seem to belong to more general cognitive processes affecting the way humans build judgments on reality:

People are nearly-incorrigible "cognitive optimists." They take for granted that their spontaneous cognitive processes are highly reliable, and that the output of these processes does not need re-checking (Sperber et al., 1995, p. 90).

This tendency to reduce accuracy (as soon as we find some pretext to do so) belongs to the results of the selective pressure under which our cognitive processes have evolved. We form our judgments through "fast and frugal" euristics balancing quality of results and expenditure of processing resources. Instead of reaching perfect, error free judgments that would cost a lot, we tend to use fast, effort-saving, approximate and partly superficial judgments:

This should not be regarded as a defect in the system though, as Tversky and Kahneman (1974), or more recently Gigerenzer (2008) have shown: heuristics are the results of an evolutionary drive in optimizing cognitive efficiency as they offer the best balance between speedy derivation of new knowledge and costly inferential thorough evaluation processes. As such they offer fast and reasonably robust means of acquiring new knowledge at a fraction of the cognitive cost. [...] our cognitive system tends to privilege fast and economical processes over reflective ones, thereby giving prevalence to cognitive illusions (Oswald et al., 2016, p. 525).

This tendency is even increased by specific factors when it comes to verbal communication. Since the progression of speech in ordinary communicative situations is fast (Christiansen and Chater, 2016), processing must be done quickly, and attention cannot be high on all contents. Linguistic utterances convey more information than our brain can process in the corresponding time, so part of that information constantly remains unprocessed, or is processed in a shallow way. If we tried to process and evaluate thoroughly all parts (including the less important ones) of utterance contents, we would dwell excessively on the first utterance and we would immediately be unable to process the essential parts of the following ones. This produces what Christiansen and Chater call a Now-or-Never Bottleneck, imposing to process any content as soon as it appears and without dwelling on it: "If the input is not processed immediately, new information will quickly overwrite it." In other words, we must 
manage to understand each chunk of information immediately, and what we do not understand perfectly at once we must accept not to understand anymore, otherwise we would not follow the flow of discourse ${ }^{2}$. Related to this, since Ferreira et al. (2002) and Sanford (2002) it has been argued that our comprehension of utterances is not an "all or nothing" function. Rather, accessing meaning is a graded affair, which can happen to a greater or lesser extent, being guided by what may be called a criterion of good-enough representation. We are often content with only partial language processing, leading to incomplete syntactic and semantic representations of utterances. The extent to which this happens also depends on the actual conditions under which each communication event actually takes place, and on the importance we attribute to getting to know precisely all aspects of the different parts of utterances.

In principle, when we read written texts we are allowed more time, and we may treat all contents with complete attention. Still, the habit to process utterances as requested by the pace of natural speech (which includes deciding what parts can be devoted lesser attention) prevails also in this case. This is no wonder, because spoken language, preceding the written versions by many tens of thousands of years (and much more in its most primitive forms), shaped the resources and the very mechanisms by which our brains process linguistic input. These mechanisms are applied to all forms of language we are exposed to, including those (like writing) that have arisen more recently. In any case, as confirmed by many of the experiments we will cite in section The Starting Hypothesis: The Brain Processes Differently What Language Presents Differently, the difference between listening and reading is not that relevant from the point of view we develop here.

How do we choose what to process thoroughly, and what to process in a shallower way? As we have already hinted at, the egocentric bias leads us to devote full critical attention to what speakers assert, and to be more optimistic on the contents we at least partly attribute to ourselves. To use a term proposed by Sperber et al. (2010), implicit contents may be processed with less epistemic vigilance. We tend not to double-check what we feel as coming (at least in part) from ourselves. At the same time, language provides means by which utterances themselves can come with cues on what needs more thorough processing and what can be controlled in a more approximate way. We propose that, typically, presupposed and topicalized contents are signaled as requiring less attention than asserted contents, for the reasons we will expose in the following sections.

Considering the above, as concerns the probabilities to be critically evaluated, linguistic implicit strategies are (for advertisers and persuaders in general) the best approximation of visual signals offered by language, since addressees who process implicit information are less inclined to recognize something wrong in it. For example, addressees reconstruct by themselves the content of implicatures: as a consequence, they will trust those contents better than asserted ones (cf. Reboul's and Mercier's

\footnotetext{
${ }^{2}$ Awareness on this state of affairs can be traced back at least to the first studies on the fact that our processing resources are limited, such as Miller (1956), where some of the essential ideas on the matter are already to be found.
}

suggestions quoted above, and Lombardi Vallauri, 1995, 2009a, 2016, 2019). Presuppositions are different from implicatures in that they can encode their content overtly, but at the same time they propose it as if it already belongs to the common ground (Stalnaker, 2002) or the shared knowledge (Strawson, 1964), i.e., as information already possessed by the addressee (cf. also De Saussure, 2014). This is an invitation not to doubt it and not even to check it. In the described general need to find contents that we are allowed to process in a shallower way, the drive to evaluate implicated and presupposed contents less attentively than asserted ones can become decisive.

In previous work (Lombardi Vallauri, 2016, 2019), I have proposed that implicit strategies can be divided into two main categories: Implicit content and implicit responsibility. Implicitness of content is represented by linguistic strategies where some content, although conveyed by the utterance, is not overtly encoded in it. This happens typically for implicatures, and for vague expressions, including metaphors.

In this contribution, we will focus on the functions of implicit responsibility.

\section{IMPLICITNESS OF EVIDENTIAL RESPONSIBILITY AS A TRIGGER OF LESSER ATTENTION}

Speakers can avoid presenting themselves as the only source for what they say. In other words, they can encode some content explicitly, but at the same time avoiding assumption of evidential responsibility for that content at least in part. In this case, which as we will see is represented by presuppositions and topics, it can be said that what remains implicit is not the content of the message, but the responsibility of the speaker for introducing it. The responsibility may still be there, i.e., the speaker may actually be the only source for that information in the communicative exchange, but this is not explicitly acknowledged, as it would be if it was asserted ${ }^{3}$.

\footnotetext{
${ }^{3}$ We must avoid a possible misunderstanding about what we mean here by "responsibility". It is not synonymous with what some literature better defines as "commitment." For example, Mazzarella et al. (2018) devote their attention to "the social and interactional dimension of commitment," which they inquire by checking conscious judgments given by experimental subjects when explicitly asked to recall past utterances and evaluate their utterers' behavior. In this perspective commitment, and-by extension-responsibility is conceived as the accountability the speaker faces, in case of subsequent, explicit challenging of their utterance, for having transferred its content.

Here, on the contrary, in a properly linguistic perspective, by "evidential responsibility" we mean (1) the evidential status (Aikhenvald, 2004) of the part of an utterance whose content is presented as not asserted by the speaker but as just resumed from previously shared knowledge (for a unified account of evidential status and information structure, including presuppositions and topics, cf. Masia, 2017, chapter 3); and (2) the consequences of this evidential status on addressees' attention during spontaneous, largely semi-conscious on-line processing.

(1) means that, from an evidential point of view, presupposed contents are presented as possibly including among their sources not (only) the speaker, but (also) previous knowledge by the audience.

(2) means that a consequence of this may reasonably be lesser vulnerability of presupposed contents to critical judgment, due to less attentive checking of their truth during online processing.
} 


\section{Presupposed Content Is Presented as Already Agreed Upon}

An utterance can explicitly encode some content, but without asserting it; i.e., presenting it as already shared and belonging to the common ground, thus skipping what De Saussure and Oswald (2009) describe as prise en charge, or engagement about the conveyed content. In Stalnaker's (2002, p. 701) words,

to presuppose something is to take it for granted, or at least to act as if one takes it for granted, as background information-as common ground among the participants in the conversation.

Presuppositions "skip" the step of proposing some content to the addressee, as if the speaker is not really transferring that content. With assertions, the speaker acts as if (s)he wants addressees to get to know something (and believe it). With presuppositions, the speaker acts as if (s)he believes that addressees already know some information, or at least they already agree to treat it as something they know: as a consequence, the speaker does not need to assert that content, and (s)he just resumes it in order to make the rest understandable. By presupposing, it is suggested that responsible for certain content is not the speaker, but some other situation causing previous knowledge in the addressee. This suggestion, operating together with the egocentric bias and the fact that sales-resistance is not needed when there seems to be no seller, gives the addressee less reason to activate his/her critical judgment: we don't need to carefully check what we already agree upon. Givón (1982) includes this effect of presuppositions in what he calls their "unchallengeability."

That some parts of linguistic messages are processed in a shallow way was shown for example by the "Moses Illusion Test" by Erickson and Mattson (1981). Experimental subjects were presented with questions like the following:

(1) How many animals of each kind did Moses take on the Ark?

The great majority answered "two," and did not notice that according to the Bible Noah, and not Moses, took animals on the Ark. This is due (at least also) to the fact that the wh- question presupposes that Moses has put animals on the Ark, as a mere starting point for asking: how many of each kind?

Importantly, the amount of information that addressees remain unaware of can vary. In the Moses Illusion Test, subjects got that the utterance involved a patriarch, but they did not notice that it was the wrong one. Utterances can be designed in order to obtain that awareness extends to indisputable contents, while possible flaws of the message remain unperceived (cf. section Presupposition Distraction and Relevance Theory below). Persuasive texts extensively exploit this rhetorical device (Lombardi Vallauri, 1995, 2019). For example, the 2019 Trenitalia advertisement in Figure 2, while apparenty asserting the uncontroversial fact that Frecciarossa trains represent high speed in Italy, more usefully exploits the existence-and-uniqueness presupposition associated to the definite description "la firma dell'alta velocità italiana" ("the signature of Italian high speed") to falsely convey that Trenitalia is the only representative of Italian

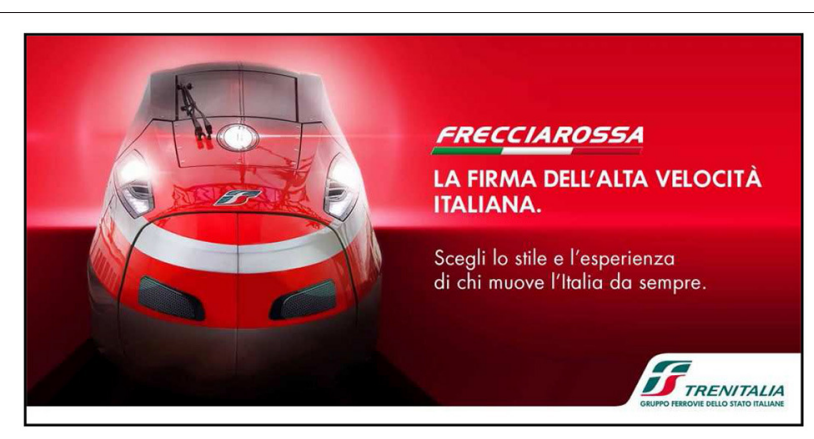

FIGURE 2 | Frecciarossa. The signature of Italian high speed.
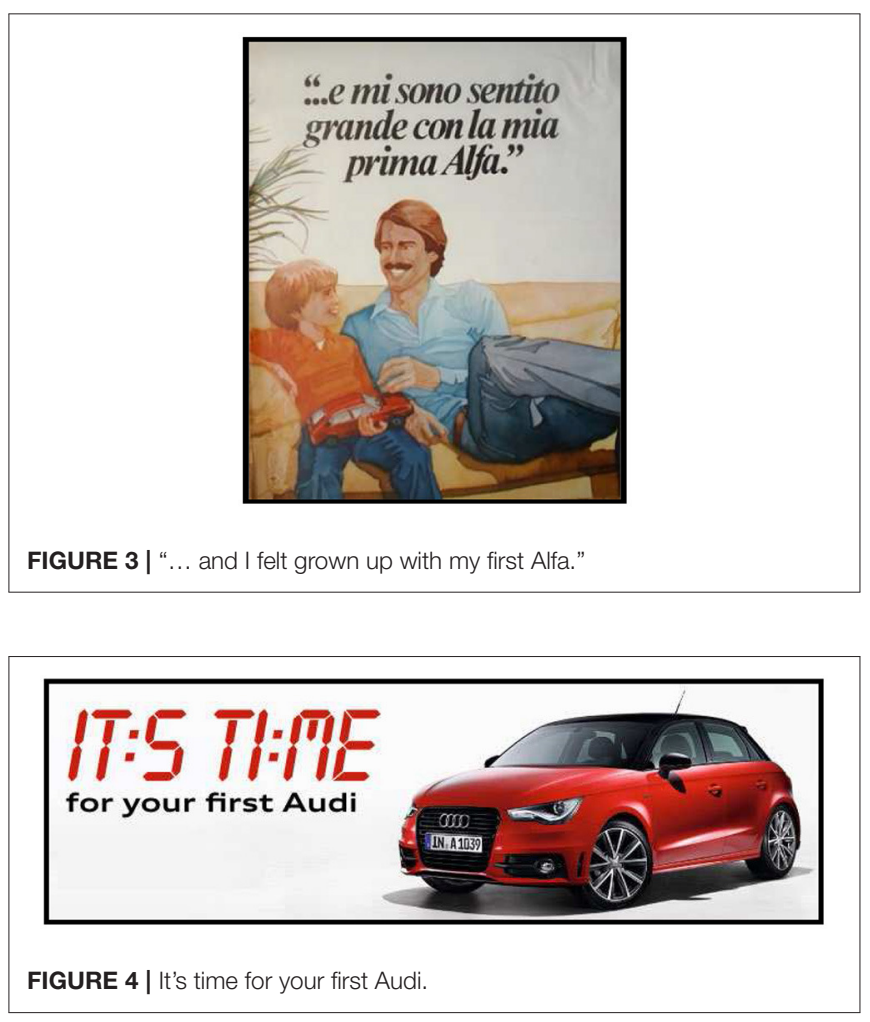

high-speed trains; which implicitly obscures the existence of Trenitalia's recent antagonist Italo-NTV.

Although a statement such as "Italo does not really count as high-speed trains" would be recognized as false by any Italian if directly asserted, the presupposition can do something to create this very impression in the target's minds. The fact that the ad is aimed against Italo at least as much as it is in favor of Trenitalia is confirmed by the subsequent specification contained in the page: "scegli lo stile e l'esperienza di chi muove l'italia da sempre" ("choose the style and the experience of those who have moved Italy eversince"), which actually underlines the only element (temporal precedency) that makes Trenitalia indisputably superior to its competitor.

Presuppositions, to some extent inadvertently, push us to reconstruct and accept as existent situations which one moment 
before were not in our knowledge of the world. For this reason they have been defined as effective strategies to "introduce information without calling attention to it” (Loftus, 1975, p. 572). This happens with the presuppositions triggered by the adjective first in Figures 3, 4 (separated by 30 years), which presupposes the following, very selling idea: "(the mentioned cars are so satisfactory, that) who buys an Alfa Romeo or an Audi car will go on buying cars of the same brand." If it were linguistically packaged as a direct statement, the same idea would be more easily recognized as false.

Unsurprisingly, also political communication makes great use of presuppositions. For example, complex definite descriptions are used to presuppose states of affairs (i.e., to hint at a preexisting agreement thereabout on the part of listeners) which most addressees would hardly agree upon if they were proposed in assertive form, because this would raise their epistemic vigilance:

(2) C'è qualcuno qua dentro che dopo aver avuto in tasca per qualche anno quella moneta criminale chiamata "euro" pensa di averci guadagnato qualcosa? (Matteo Salvini, Milano, January 28, 2016).

Is there anyone here who, after having that criminal currency called "Euro" in his pockets for some years, thinks he has benefited from it?

Even using such strong terms, which can hardly pass unnoticed, an expression like "that criminal currency called Euro" enjoys some sense of unquestionability which it would not exploit if it was proposed via assertion: "Euro is a criminal currency." Beyond the persuasive power of each example, this seems to be a process dear to Italian politicians (Lombardi Vallauri, 2019). Just to quote a second example, from a speech in the Italian Senate:

(3) Su questa storia delle banche ci sarebbe da dire tanto. Eh, all'inizio di questa legislatura, quando il Governo Letta avviò questa serie di regali alle banche, chiaramente intuimmo che c'era una certa connivenza del Partito Democratico con il sistema. Poi si è scritto invece moltissimo sull'incapacità di questo Governo, (...) (Barbara Lezzi, Senate of the Republic, July 27, 2017).

On this affair of the banks there would be much to say. Euh, from the beginning of this term, when the Letta government started this series of gifts to the banks, we clearly sensed that there was a certain collusion between the Democratic Party and the whole system. Then, very much has been written on the inability of this government...

The impression that "this series of gifts to the banks" or "the inability of this government" were matters of established truth was better obtained by using definite descriptions, than by asserting that "the Letta government has made a series of gifts to the banks," or that "this is a government of incompetents": such assertions would have raised more careful evaluation, and their being at least exaggerated would have become clearer to the target.
Not only definite descriptions, but also other presupposition triggers are used in political communication to convey questionable contents. Here Matteo Renzi, referring to the possible outcome of the constitutional referendum, by means of a change-of-state verb presupposes that Italy is no longer a reference point for anyone:

(4) L'Italia torna ad essere un Paese che può essere punto di riferimento, per la cultura e per i valori nel mondo (Matteo Renzi, Firenze, December 2nd, 2016).

Italy returns to being a country that can be a point of reference, for culture and the values in the world

When Donald Trump (and Ronald Reagan before) said that they would

\section{(5) Make America great again}

they were using the same linguistic strategy, presupposing that under their predecessors America had lost its greatness. The same content, if asserted instead of taking it for granted, exactly in the same situations, would have gathered much less agreement: "America in no longer a great Nation."

\section{Topicalized Content Is Presented as Currently Active in the Addressee's Attention}

As defined by Cresti (2000), Topics are utterance parts that do not perform illocution, and this is typically due to their content being something the participants are presently thinking about (Lombardi Vallauri, 2009b, 2019), i.e., what Chafe (1987, 1992) calls contextually activated, "Given information," as opposed to New information, the encoding of the latter being typically entrusted to the Focus of the utterance. In other words, while presuppositions hint at the presence of some information in the participants' long-term memory (something "known," but not necessarily being presently thought of), topics present their content as active in the participants' short-term memory at utterance time. These are quite different things (Lombardi Vallauri, 2009b, 2019), but we can disregard this kind of difference here for our present purposes. With topics, exactly as with presuppositions, a content is introduced by hinting at its being already in the possession of the addressee(s). Consequently, addressees may be tricked by the egocentric bias into devoting less epistemic vigilance to information in topic status, which in turn may lead to doubtful contents being more easily accepted. Bredart and Modolo's (1988) manipulation of the Moses Illusion Test was aimed at showing that some information will be processed vith varying depth according to different linguistic packaging. By changing the syntactic structure of the original question, they obtained two different assertions, each with a cleft construction. Crucially, Moses belonged once in the focus (F) and once in the topic $(\mathrm{T})$ of the utterance:

(6) It was $[\mathrm{MOSES}]_{\mathrm{F}}$ who [took two animals of each kind on the Ark $]_{\mathrm{T}}$

(7) It was [TWO ANIMALS $]_{\mathrm{F}}$ [of each kind $]_{\mathrm{T}}$ that $[$ Moses took on the Ark $]_{\mathrm{T}}$ 
As expected, subjects noticed the error when Moses was focalized, and they missed it more often when it was topicalized.

Something similar is at work in (8) and (9), taken from political speeches by Paola Taverna and Matteo Renzi. The speaker prefers not to present some content as introduced by her/himself, but rather as already available to her/his addressees by virtue of the ongoing circumstances. Encoding it as a topic (here underlined) allows her/him to suggest that the activation of that content in the discourse model is not her/his entire responsibility, and that (s)he is just recalling it, in order for addressees to understand her/his point, which is encoded in the focus.

(8) Insomma un delinquente abituale, recidivo e dedito al crimine, anche organizzato, visti i suoi sodali.

In sum, a habitual offender, recidivist and devoted to crime, even organized, given the friends he has.

(9) Dall'altro lato, un'idea di Europa che in questi anni non ha funzionato, ha fallito.

On the other side, an idea of Europe which hasn't worked in these years, has faile $\bar{d}$.

In (8), Mr. Berlusconi's having friends in criminal organizations is presented by Taverna as already active in the hearers' consciousness, as something they have got from recurrent mainstream narration: in other words, as not being the speaker's fabrication. In (9), Renzi encodes as a topic (prosodically marked, as the starting point of the utterance) his opinion that "a certain idea of Europe" has not worked. This hints at such an idea being given information, a well-known state of affairs, not a malicious insinuation on the part of the speaker.

In the eighties the Italian government diffused a pro-Europe advertisement (Figure 5) which, by means of a topical purpose clause, presented the aim of "entering Europe" as already widely shared.

Better than any overt statement ("You/We all desire to be "part of Europe'!"), presenting the same content as already activated in the discourse model of the utterance was effective in making readers inadvertently accept the idea that they had always wanted to be part of Europe.

With these examples we have briefly shown that topics, similar to presuppositions, while overtly encoding some content, nevertheless dilute the role of the speaker in introducing that content. Further, we have shown that this diverts critical attention from that content. Better said, topics allow the speaker not to assume the evidential responsibility for a (well-chosen) part of the message, and to give the target the impression that they already have that content in mind.

In the next section we will propose an explanation for these facts, based on the different functions of presuppositions, conceived as "background" information (Lombardi Vallauri, 2009b, 2016, 2019; De Saussure, 2013). The same could be shown for topics (cf. Lombardi Vallauri and Masia, 2015; Lombardi Vallauri, 2016, 2019), but we lack space to do it here in detail, so we will only mention topics here and there by analogy with presuppositions.

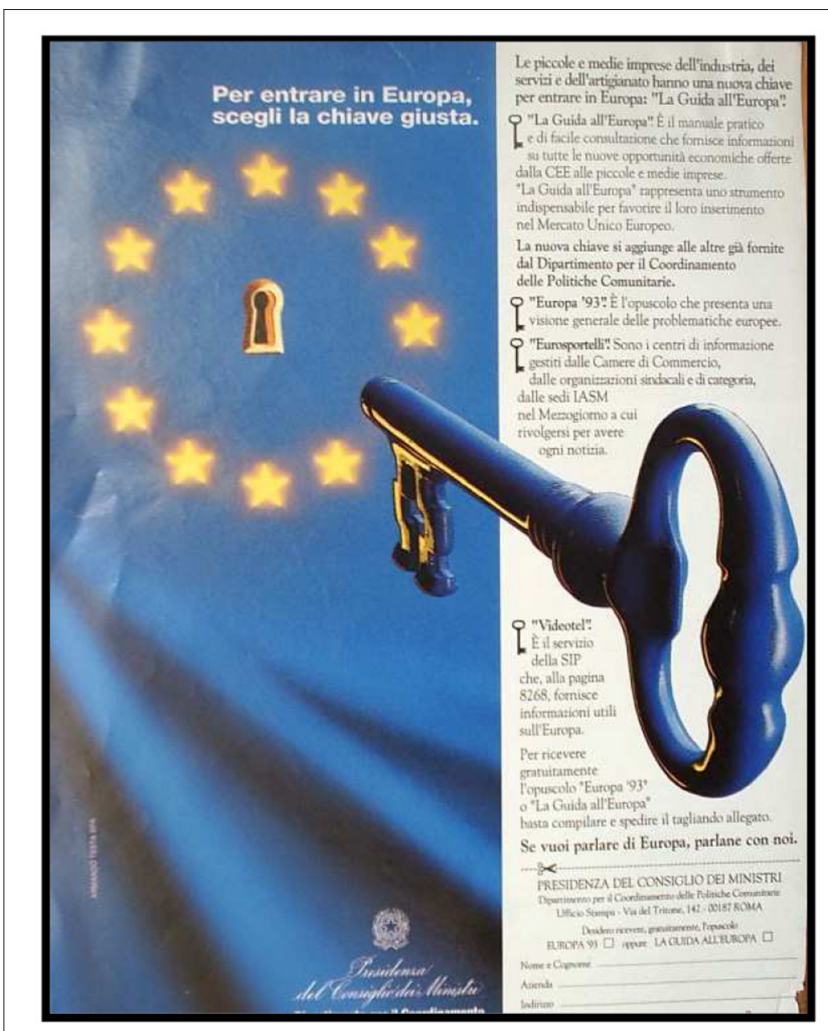

FIGURE 5 | To enter Europe, choose the right key.

\section{MULTIPLE FUNCTIONS OF PRESUPPOSITIONS: ECONOMIC AND PERSUASIVE REDUCTION OF ATTENTION}

\section{Effort-Saving Presupposition of Already Shared Information}

The use of presupposing and topicalizing expressions is motivated by economy of effort. When the addressee already knows about some content, the speaker must act accordingly, and present that content as presupposed. Asserting that content would instruct addressees to treat it as something new. Consequently, they would concentrate attention on it and would udertake to establish it as new information in their set of knowledge. In the fabricated utterance (10), each piece of information is asserted, as if the addressee is completely unaware of it:

(10) I exist. I was born. You have a mother. I also have a mother. Your mother used to have a car. There are cities. One is called Berlin. There are films, and festivals, and film festivals. They organize one there. There are periods called months, and one of them is called February. There are years, and one had number 2001. Your mother drove mine there in that car before that happy event, on that month of that year.

Each assertion tells the addressee to focus on the encoded chunk of information, and create a new mental position for the person of the speaker, one for the speaker's being born, one for a mother 
of hers/his, one for a mother of the speaker, one for a car of hers, one for some city called Berlin, one for months and specifically for so-called February, etc. This will cause what Masia et al. (2017) have proposed to call a "pragmatic garden path" effect. In fact, immediately after attempting to treat them as new contents, the addressee will obviously realize that such slots already exist in her/his mind, and are already filled by the corresponding referents. In other words, that (s)he already knows about the existence of her/his own mother, the speaker's mother and the speaker's being born, Berlin, February, etc. The speaker can avoid addressees this waste of processing effort, by using presupposing expressions like in (11) (namely, a temporal subordinate clause and several definite descriptions). This tells the addressee that (s)he can treat those contents as something (s)he already knows, and in particular that (s)he can process them less carefully: not the effortful way that would be needed to establish them ex novo in her/his memory, but just what is needed to recognize them in $\mathrm{it}^{4}$.

(11) When I was about to be born, your mother drove my mother with her car to Berlin to see the Film Festival of February 2001.

By presenting (here, by means of definite descriptions) the existence and identifiability of her/his mother (or Berlin, or February) as presupposed, i.e., as already shared, the speaker saves the addressee unnecessary effort. The same if the speaker's birth is presented as presupposed information via a temporal clause. Since the linguistic packaging characterizes that content as already known, the addressee feels "authorized" to pay less critical attention to it: carefully evaluating that piece of information would mean repeating a task one has already performed. In order to understand the new, not previously known part of the message ("she drove her there then"), the already known part ("I was born," "my mother," "Berlin") can be devoted just a shallow, resumptive recollection.

\section{Effort-Saving Presupposition of Marginal Information That Can Be Accommodated}

We have just proposed that expressions presupposing their content probably arose in order to ensure very convenient economy of processing effort where it is possible. But they have acquired further uses, with a mechanism that somewhat resembles the evolutionary phenomenon of exaptation (Gould and Vrba, 1982), which applies in animal and human development, where a feature that used to perform a certain function can extend its domain of application to one or more other functions. Linguistic packaging aimed at saving processing effort by reducing critical attention on information already known by addressees can also instruct to save effort on information which, although it is not previously known, can be allocated less attention because it is marginal, and only needs shallow

\footnotetext{
${ }^{4}$ Neurologically speaking, this roughly corresponds to the difference between linking some content to the existing mental register, and updating the register. For the way this distinction affects the processing of presuppositions, $\mathrm{cf}$. Domaneschi et al. (2018).
}

processing in order for the main part of the message to be understood.

If this can be seen as a step of exaptation only by metaphor or also in a more technical way, it is difficult to say, given that we don't know anything about the presence and use of presupposing structures in early stages of language. Linguistically suggesting addressees that they already know about something when they actually know, and doing the same for marginal but new information as if they already know about it, may be regarded as logically consecutive functions. But this does not guarantee that also chronologically, in early stages of langage, the second has developed from the first. They may well have arisen together.

When some content is presented as presupposed even if it is unknown to addressees, usually accommodation (Lewis, 1979) takes place, i.e., the fact that addressees tacitly accept to treat it as if they already agree on it. In (12), addressees will probably accommodate the presupposition triggered by the transformation verb cancel:

(12) Please, call Vanity Fair and tell them I want to cancel my subscription.

Supposing that the addressee is not aware that the speaker is a subscriber to Vanity Fair, the speaker might say:

(13) I currently have a subscription to Vanity Fair. Please, call them, and tell them I want to cancel it.

But asserting information on the existence of the current subscription causes redundant effort, which can be avoided by just presupposing the idea that it exists, as if the addressee already knows about it, while the request to call and unsubscribe is fully encoded, so that the addressee devotes major processing resources only to the latter. In sum, the reason why (12) would be preferred to (13) in many situations is that it saves processing effort, only requesting the addressee's full attention where it is really needed.

\section{Presupposition of Questionable Information Diverts Attention From Less Convincing Details}

The economic uses of presuppositions we have just described have a third function as their side effect. Beside economy of effort, inducing shallow processing on new, unknown contents also result in preventing full understanding of those contents. Thorough processing, when some content happens to be false or at least doubtful or exaggerated, leads addressees to realize they do not agree with it. But if they process it with less attention they may skip delving into its questionable details, and accept the core message as valid (cf. Section Presupposition Distraction and Relevance Theory). The flaws of some questionable information are easier to detect when it is asserted, but may elude receivers' attention if they undergo the shallow processing which is typically associated to presupposed, "already known" contents. The latter also holds for the status of already active information, which is suggested by topic constructions.

As we have already seen, persuasive texts systematically exploit this proceeding. Just to add some more examples, in the 


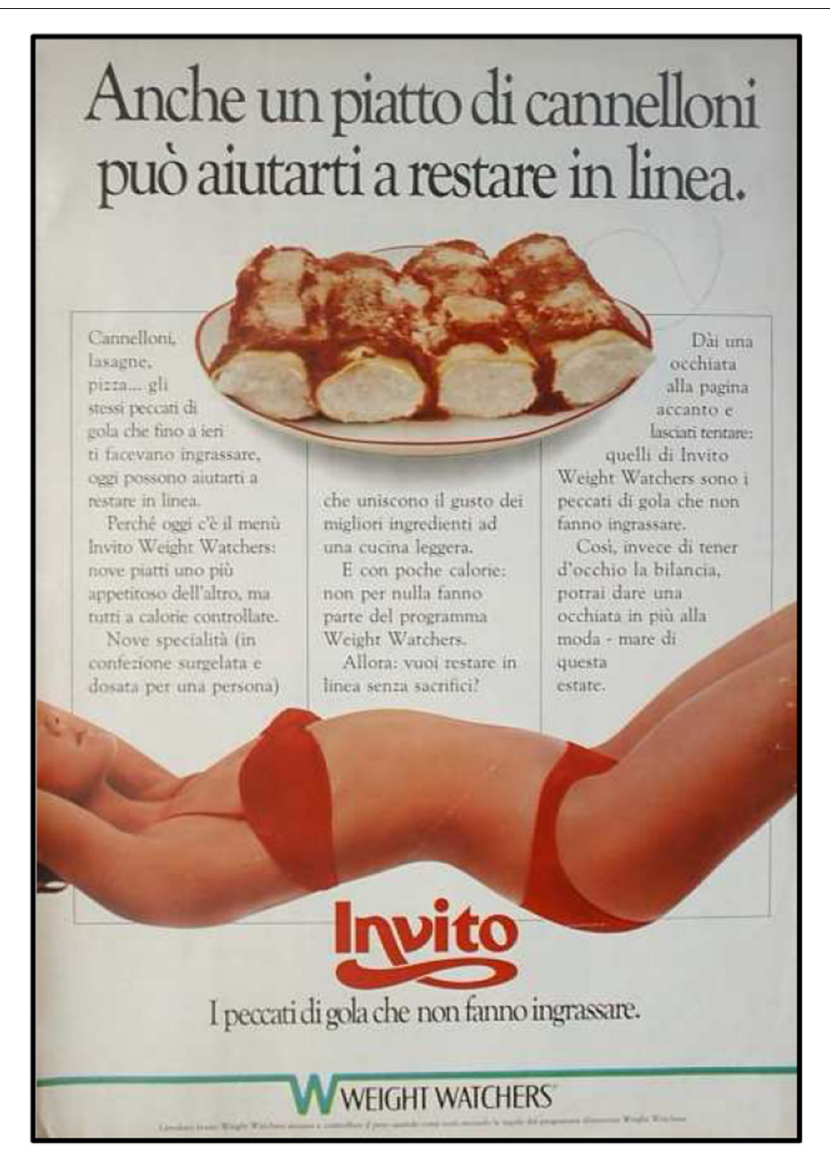

FIGURE 6 | Invito. The sins of gluttony that don't make you fat.

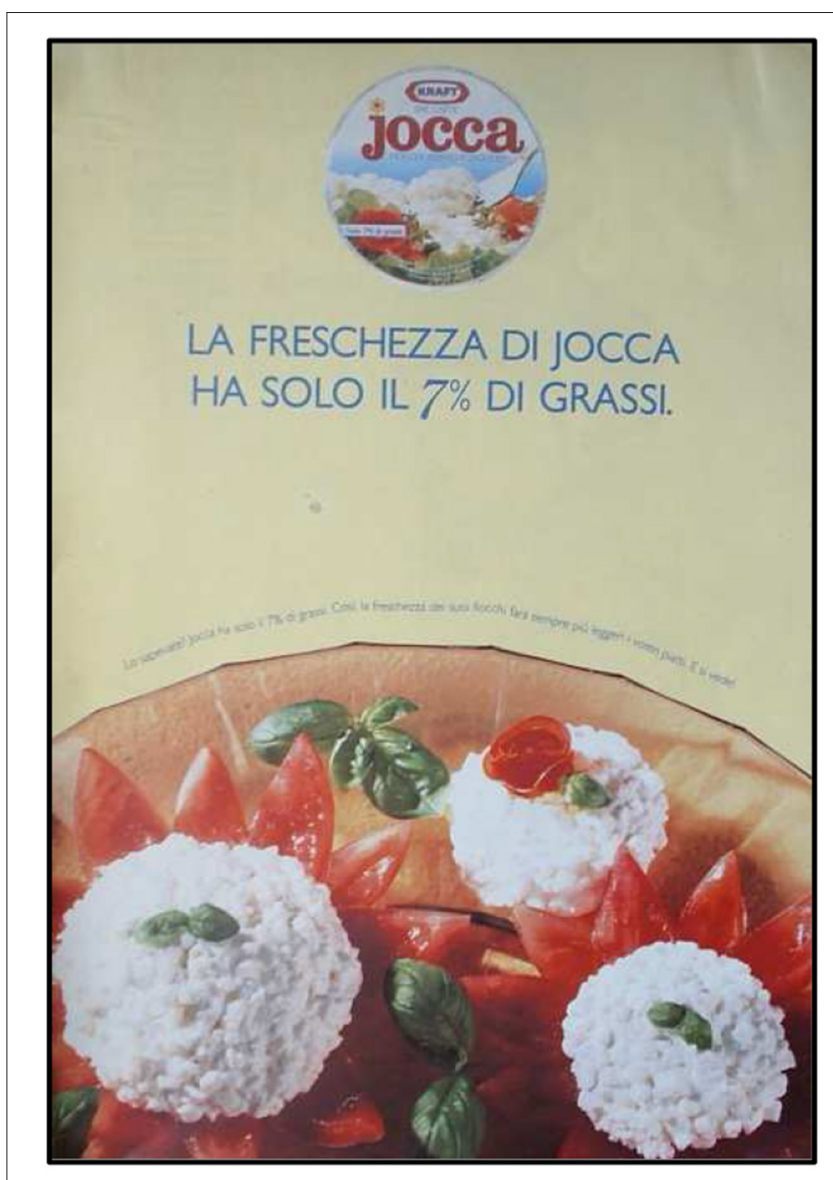

FIGURE 7 | The freshness of Jocca has only $7 \%$ fat. nineteen-eighties advertising of dietetic products in Italy definite descriptions were constantly used to presuppose questionable but selling concepts. The ads in Figures 6-8 all display the same structure. In purchasing low-fat products, people's choices are guided by the hope to experience good taste. With this kind of products, low fat content is obvious, pleasure is not. For this reason, the most important thing of which ads try to convince their target is that the product is pleasant to eat. The slogans in Figures 6-8 try to do this. Assertions draw attention (and innocuous critical evaluation) to trivial truths about their low fat content, while the decisive notions about organolectic pleasure are entrusted to presupposing definite descriptions, which divert critical attention that may lead the target to recognize the exaggeration or even falsity of contents such as "the sins of gluttony," "the freshness of Jocca" and "the new taste," referred to the advertised products. If the ads asserted directly: "Invito Weight Watchers are sins of gluttony" or "Mayonnaise Vive la Vie is the new taste," such claims would hardly be believed. Only the shallow processing caused by their being presented as presupposed, i.e., as already widely shared assumptions, allows for them not to be critically challenged and recognized as exaggerated or false.
Even contents that may offend the addressee become acceptable if presupposed. The headlines of the Citroên and Renault advertisements in Figures 9, 10 presuppose that the reader has "closed eyes," is "watching the world with the eyes of other people," and that (s)he is watching life instead of living it. Change-of-state verbs such as open, stop and start, and the negative imperative (don't watch the world...) convey presuppositions that readers are living poor lifes and implicatures that they will improve them by buying the advertised cars. If asserted, statements such as You are just watching instead of living, because you do not drive a Renault Kadjar, or You are watching the world with other people's eyes would be immediately recognized as false and offensive. The reason why the ads succeed in transferring such indigestible contents and in having them accepted by the target is precisely that they encode them as presuppositions. This causes for them to be processed in a more generic, less attentive way, to the point that their being false and offensive passes unnoticed. Attention is rather driven to the positive suggestions to open one's eyes and live one's life, that are expressed by the non-presupposed parts of the utterances. Obviously, also presuppositions triggered by the adjective "first" that we have seen in Figures 3, 4 above have the same function. 


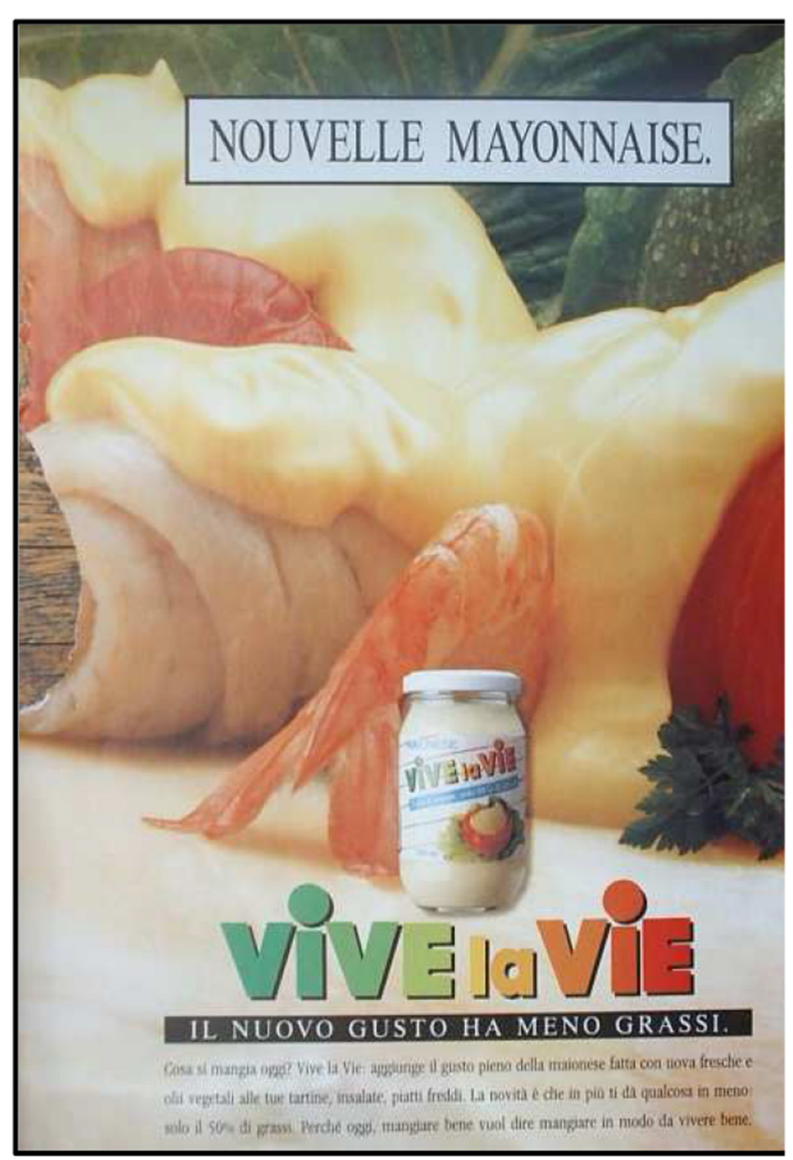

FIGURE 8 | Vive la Vie. The new taste has less fat.

\section{The Three Processing Functions of Presuppositions: A Summary}

Sections Effort-Saving Presupposition of Already Shared Information, Effort-Saving Presupposition of Marginal Information That Can Be Accommodated, and Presupposition of Questionable Information Diverts Attention From Less Convincing Details can be summarized as follows. Presupposition $^{5}$ always instructs the addressee to pay less attention, i.e., as we will see below, to devote less processing effort, to certain content. The actual pragmatic purposes associated to shallower processing depend on what the cognitive status of the presupposed contents is in the set of knowledge of addressees at utterance time:

- When a content is already shared by addressees, conveying it through a presupposition will save addressees the cognitive effort to process it as if it was new information, which would be redundant.

- When a new content is trivial or marginal to the understanding of the message and at the same time it is simply true and out of question, conveying it through a presupposition will

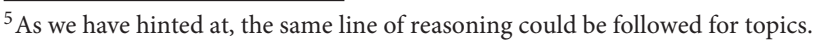

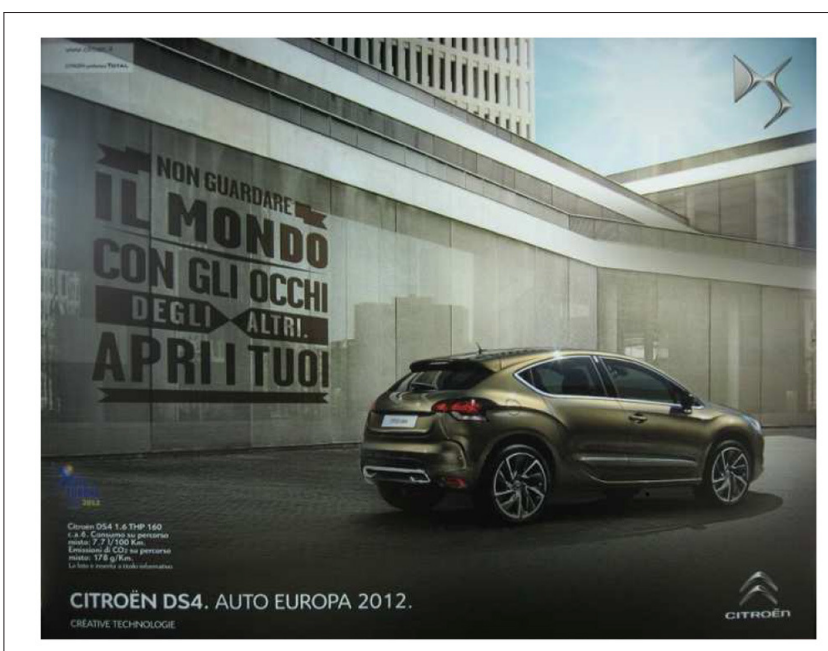

FIGURE 9 | Don't watch the world with someone else's eyes. Open yours.

save addressees the effort to process it thoroughly, which will prove an advantage because the core of the message will be understood all the same.

- When a content is not shared by addressees and also false, exaggerated or questionable, conveying it through a presupposition will again induce addressees to shallow processing, which in this case may result in low awareness of the flaws and poor credibility of that content. As a result, addressees may more easily accept contents that they woud reject if encoded in assertive form.

\section{PRESUPPOSITION DISTRACTION AND RELEVANCE THEORY}

It may be interesting to assume a closer, more "micro" perspective on the process leading to acceptance of questionable contents when they are presupposed. We may try to inquire more in detail how the acceptance of a presupposition's core content is made possible by the unawareness of its more doutful aspects. In fact, the phenomena we have described so far seem highly compatible with some recent proposals that have been advanced within Relevance Theory. In particular, they seem to parallel the manipulative strategy described for argumentation processes by Maillat and Oswald (2009). We will try to explain why.

The way we create ad hoc concepts (Barsalou, 1992) to select the referents of linguistic expressions in actual utterances depends on many factors. Among these, there is one that can be systematically exploited to realize manipulative purposes. As we have said, and as Maillat and Oswald put it:

manipulation exploits the way our mechanisms of information processing work; that is, a necessarily imperfect and biased way (Maillat and Oswald, 2009, p. 360).

One bias that can be effectively exploited is tendency to least effort. This tendency causes shallow processing whenever possible. As a consequence, moreoften addressees do not build 


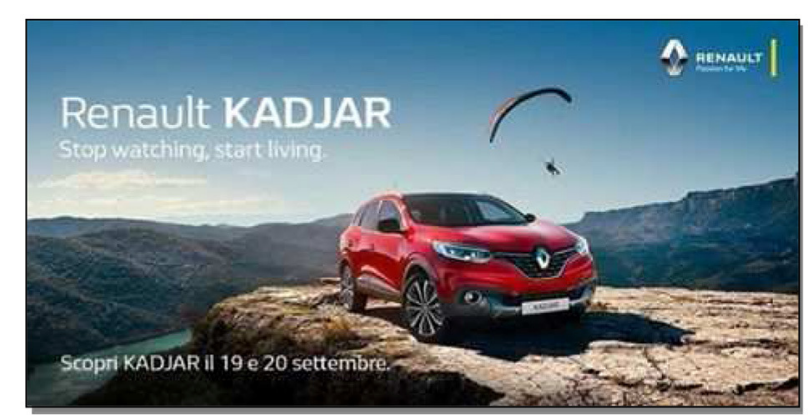

FIGURE 10 | "Stop watching, start living."

in their mind a complete representation of the things mentioned by the source. Rather, they build some partial and more restricted concept, by retrieving from their memory not all the objects that the expression may describe, but just part of them. If the source says The Government, retrieving all we know about the idea of "government" would be a waste of effort, and would distract us from following the ongoing discourse. Therefore, we evoke a narrower concept of government, made of the features that are relevant in that discourse model. For example, if discourse is about taxation, we conceive of the government as fiscal legislator. If about the country's constitutional system, we evoke the government as exercising executive and legislative power. If the discourse is about political competition, as "government" we may understand mainly the political majority as opposed to the opposition parties, and in that case its role in charging taxes does not rise at the level of our conscience. To quote Allott and Rubio Fernández (2002, p. 99), each ad hoc concept is

constructed by retrieving from an existing concept in longterm memory some but not all of its encyclopedic and logical information. The new concept may be narrower or looser than the concept it is derived from.

Maillat and Oswald point out that one manipulative strategy consists in distracting addressees from those features of concepts that may make it easier to recognize the falsity or the low credibility of the manipulative argumentation. In order to distract them from such features, the manipulator draws the addressees' attention to other features of the concept he expresses, more favorable or at least harmless for his point of view. As a consequence, addressees create ad hoc concepts that are suitable to persuade them, instead of concepts that would lead them to reject the manipulator's argument. This is their formulation, in more technical terms:

a manipulative speaker will be taken to increase the accessibility of a certain subset of contextual assumptions, C, within which the target utterance will be almost inevitably processed (from a cognitive perspective), so as to ensure that the addressee does not process the target utterance within a larger context, $C^{\prime}$, in which it might appear inconsistent or contradictory with some prior background knowledge he upholds (Maillat and Oswald, 2009, p. 365).

The distraction effect, favored by shallow processing, is obtained by foregrounding the information $(\mathrm{C})$ that will induce addressees to create ad hoc concepts favorable to the manipulator. On the contrary, all information (C') which would induce addressees to reject the manipulator's position is backgrounded, so that it hardly contributes to the forming of the ad hoc concept. In other words, the manipulator chooses the conceptual material he submits to his target, so that they are contextually satisfied and do not feel the need to further inquire or clarify those concepts with more elements. Thus the target-also due to their tendency to economy-do not proceed further in their effort to reconstruct the meaning of the utterance, and do not discover its falseness:

Typically, the strategy adopted by a manipulator in order to prevent the addressee from accessing an extended set of contextual assumptions, $C^{\prime}$, makes use of highly salient contextual assumptions which will ensure that a degree of optimal relevance is reached before an extended context is constructed (Maillat and Oswald, 2009, p. 368).

We propose that, in this picture, an effective role can be played by presupposition, because it can induce shallower processing of certain content, inviting to build ad hoc concepts essentially based on the most acceptable parts of the message, so that the flaws, conveyed by the presupposition, do not run into the addressees' critical awareness.

This is what happens in the persuasive messages we have mentioned above: "...And I felt grown up with my first Alfa" draws full attention to the encoded idea of feeling grown up with one's first Alfa, and also evokes the idea that "then you buy more Alfas." The latter is likely to be understood by the target and to influence them to some extent, but since it is just backgrounded, presupposed information, it may not be evaluated as needed for them to become aware that it is quite a questionable assumption. Addressees, devoting as little effort as they can, are content with an extremely vague representation of the utterance, just enough to understand what seems to be its "main" content. This representation does not include those details that would foster the awareness that buying an Alfa does not guarantee that you will remain faithful to that brand.

Similarly, "Don't watch the world with someone else's eyes. Open yours" induces thorough processing of Citroên's good intentions. At the same time, it also evokes the idea that you are living without using your eyes, but since this is done by means of a presupposition, the target will most probably be content with building a shallow representation of that content, which prevents them from realizing that it is offensive.

\section{THE STARTING HYPOTHESIS: THE BRAIN PROCESSES DIFFERENTLY WHAT LANGUAGE PRESENTS DIFFERENTLY}

As we have seen, different types of linguistic packaging instruct addressees to different cognitive operations. Assertion invites to 


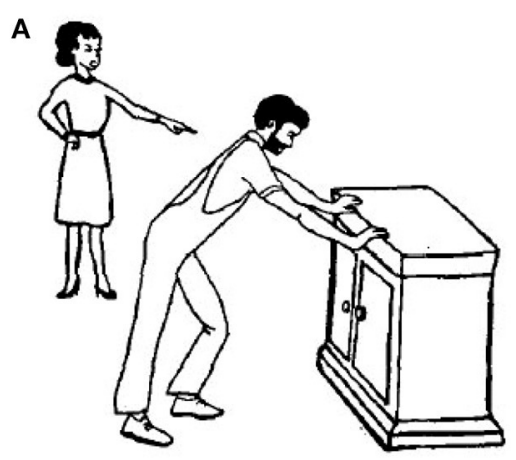

FIGURE 11 | Picture from Experiment 2 by Langford and Holmes (1979).

create a new mental item for explicitly encoded information, i.e., to "write" something new into one's memory. Presupposition instructs to recognize some referent among the things one already knows, i.e., to seek it in one's Long-Term Memory. Topics suggest that the referent is among the things that are active in Short-Term Memory at utterance time. In other words, assertions should induce addressees to increase the set of things they know, while presuppositions and topics should induce them to localize some content within the things they already know about.

This hypothesis clearly concerns the information processing activity of our minds and brains. This means that it can be checked directly, by means of behavioral and neurophysiological tests.

\section{Evidence From Behavioral Experiments}

The already mentioned Moses Illusion Test was a behavioral experiment, where the presupposition triggered by a question resulted in shallow processing of some content. Other questions similar to that on Moses/Noah gave the same results. For example: What country was Margaret Thatcher president of? (instead of Prime Minister); By flying a kite, what did Edison discover? (Franklin); Who found the glass slipper left at the ball by Snow White? (Cinderella); What is the name of the long sleep some animals go through during the entire summer? (winter). On the contrary, as we have seen, when the utterance encodes the same information without presupposing it (It was Moses who took two animals of each kind on the Ark), subjects are much more likely to notice the error ${ }^{6}$.

Among the first experiments to have tested the processing of presuppositions as compared to assertion are those by Hornby (1974) and Loftus (1975). Peter Hornby had his experimental subjects listen to some sentences describing a scene. Then they were shown the scene, and had to say whether the sentence was true or false. Actually, sentences contained an error, which was either in the asserted or in the presupposed part. When the error was asserted, subjects noticed it more frequently.

In Loftus's experiment, ${ }^{7} 150$ university students watched a 3-min film of an automobile which eventually collides with a

\footnotetext{
${ }^{6}$ This has been tested by Bredart and Modolo (1988) and by Kamas et al. (1996). Many more experiments of the kind are referred to by Sanford (2002).

${ }^{7}$ We mean here the fourth experiment of Loftus (1975).
}

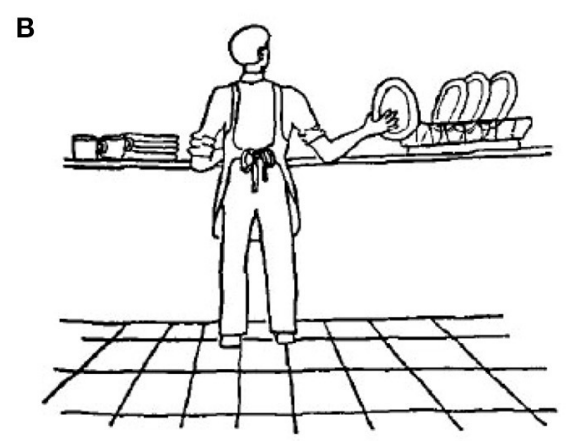

baby carriage being pushed by a man. Then they answered questions on the film. The questions encoded the idea that the film contained something, which was actually not in it. Half of them presupposed that idea, half of them directly asked it. For example:
Direct questions:
Did you see a schoolbus in the film?
Did you see a woman pushing the carriage?
False presupposition questions:
Did you see the children getting on the schoolbus?
Did the woman who was pushing the carriage cross into the road?

The movie, indeed, displayed no schoolbus, and the carriage was pushed by a man. One week later subjects were gathered again, they did not watch the film again, and they were all presented with the direct questions containing the same errors. Interestingly, the subjects who had been exposed to the wrong-presupposing questions one week earlier, now gave wrong answers in $29.2 \%$ of the cases, while those who had been originally exposed to the wrong direct questions only in $15.6 \%$ of the cases. In other words, false information had made its way into the subjects' mental representation of the film almost twice more frequently when presupposed, than when presented as new.

Experiment 2 by Langford and Holmes (1979) was based on reaction times. Subjects read written sentences [like those in (a) and (b) here below] with information about a picture (Figure 11) they were shown immediately after:

a) 1. It's the woman who is pushing the cupboard

2. It's the cupboard that the woman is pushing

3. The one who is pushing the cupboard is the woman

4. What the woman is pushing is the cupboard

b) 1. It's the man who is washing the floor

2. It's the floor that the man is washing

3. The one who is washing the floor is the man

4. What the man is washing is the floor.

After reading the sentence and watching the picture, subjects pressed a button to say whether the sentence was correct or 


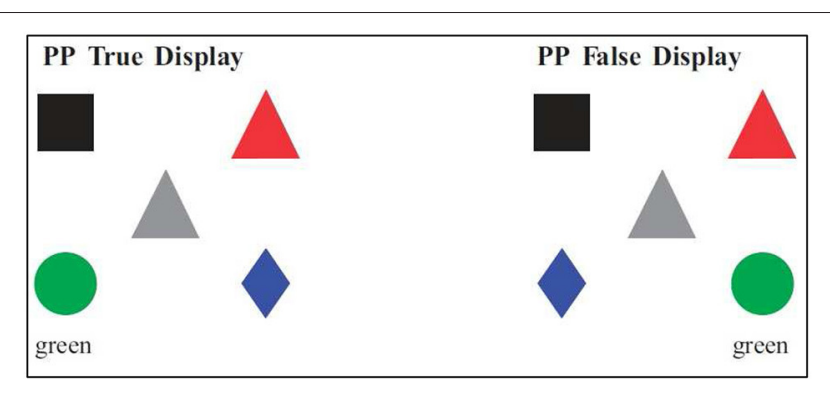

FIGURE 12 | Picture from experiment 1 by Schwarz (2016).

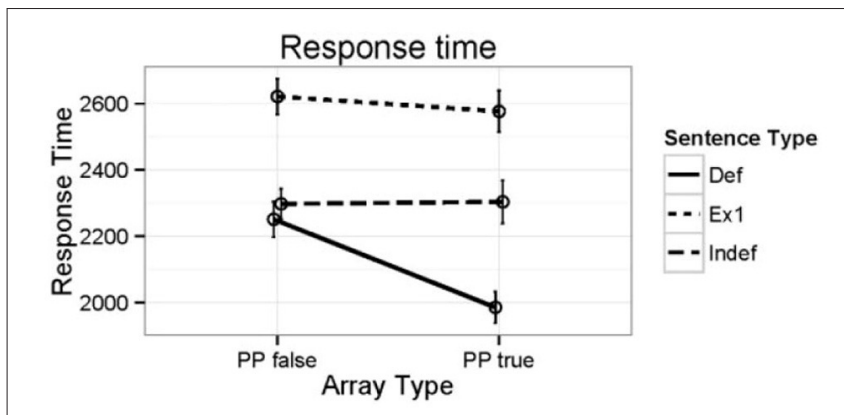

FIGURE 13 | Experiment 1 by Schwarz (2016).

not. Crucially, they took more time when the wrong information was presupposed (a2 and $\mathrm{a} 4, \mathrm{~b} 1$ and $\mathrm{b} 3$ ) as compared to when it was asserted ( $\mathrm{a} 1$ and $\mathrm{a} 3, \mathrm{~b} 2$ and b4). This can mean that the same information acquires a clearer representation in mind when it is processed as asserted, as compared to presupposed. In other words, it is more difficult to recognize the falsity of some information when presupposed, and easier when asserted.

Irwin et al. (1982) have shown that nominals presented in discourse with the definite article, i.e., presupposing the existence and identifiability of their referents, are processed faster than nominals (denoting the same concepts) with the indefinite article, i.e., presenting their referents as something newly introduced and to be processed ex novo.

Similar experiments considered topic and focus as conditions, with parallel results. Birch and Rayner (1997) found that reading times for focalized information are longer than for non-focalized, topical information, and by means of an eye-tracker they showed that subjects' gazes returned more times to words in focus than to words in topic. Sturt et al. (2004) verified that exchanging words in pairs of sentences was detected more frequently by subjects when belonging to the focal parts of utterances, as compared to the topical parts. Sentences were like the following, where in the same context the cider is once in focus and once in topic:

a. Everyone had a good time at the pub. A group of friends had met up there for a stag night. What Jamie really liked was the cider, apparently. b. Everyone had a good time at the pub. A group of friends had met up there for a stag night. It was Jamie who really liked the cider, apparently.

If cider was replaced by beer, subjects detected the exchange more frequently when it was in sentence (a), namely with the target word within the focus of the utterance, as compared to sentence (b) where it was included in the topicalized part. The authors suggest that when in topic the word cider may be processed in a shallower way, at a higher level of semantic "granularity," and understood just as a generic, superordinate concept like "drink," leading to more difficult recognition that beer introduced a different concept. This is more or less the same as the substitution of the incomplete information set $\mathrm{C}$ for the more complete set C' proposed by Maillat and Oswald (2009), which we have recalled in section Presupposition Distraction and Relevance Theory above.

Such data speak in favor of lesser time, energy and attention devoted to processing topical as compared to focal information.

More recently, Schwarz $(2015,2016)$ and Schwarz and Tiemann (2017) have produced relevant evidence that the processing of presupposed contents is faster than that of their asserted equivalents. Schwarz (2015) has monitored the eye movements of subjects who were asked to pick up the right items in a picture after listening to linguistic instructions. Such instructions contained either the adverb also or the adverb only, which, respectively presupposed and asserted the needed information. Crucially, subjects were able to pick up the right items more quickly when the necessary input was encoded as a presupposition by also, than when it was asserted by means of only ${ }^{8}$. In sum, presupposition was processed faster than assertion.

Schwarz (2016, Experiment 1) measured the time used by subjects to assess whether a sentence describing a picture they had just watched was true or false.

Subjects were shown either the left or the right part of Figure 12, respectively correctly or falsely described by both the following sentences:

a. The circle on the left was green.

b. There was a circle on the left that was green.

In (a) the existence of a green circle on the left was presupposed by means of a definite description, while in (b) it was asserted by means of an indefinite description. People basically gave right answers, correctly assessing the truthfulness or falsity of sentences with respect to the shown picture. But, crucially, time played a role. This is shown in Figure 13. Assertive sentences ("Indef" in the Figure) took the same time to be judged true or false, but presupposing sentences ("Def") were judged true more quickly than false ${ }^{9}$.

\footnotetext{
${ }^{8}$ Essentially, there was a delay of about $500-600$ ms between the two conditions. Things are more complex than that, but in a way that does not affect our discourse. For more details we refer to Schwarz (2015).

${ }^{9}$ In Figure 13, "Ex1" refers to a third condition, which does not concern us here. "PP true" and "PP false" in both Figures 12, 13 stand respectively for utterances like (a) and (b) conveying respectively true or false information with respect to the picture shown to subjects, namely the left or the right one in Figure 12.
} 
Experiment 2 by Schwarz (2016) also used sentences describing a picture. It demonstrated that subjects took more time to recognize that a content was false when it was presupposed by means of a definite description, than when it was encoded by a non-presupposing indefinite description.

All these experimental data confirm what can be inferred from the extensive use of presuppositions to convey questionable or even false information in persuasive texts (section The Presence of Implicit Strategies in Persuasive Communication, above): by presenting their content as already known and accepted, presuppositions cause shallow (faster) processing and protect that content from being recognized as false. In Schwarz's (2016) words, a presupposition

is unlikely to be critically evaluated itself (at least initially), and challenging its accuracy and detecting its falsity comes with additional processing efforts.

This additional effort, in the absent-minded fruition of an advertisement or in the fast flow of a propaganda speech, is likely not to be done. Copywriters and politicians who use presuppositions to convey doubtful contents do not make psycholinguistic experiments, but seem to know these processes well.

\section{Behavioral Evidence: A Provisional Summary}

The behavioral data we have reviewed strongly speak for two assumptions, which ground the persuasive effectiveness of the implicitness of evidential responsibility obtained by presuppositions and topics.

1. Presuppositions and topics are processed faster and in a shallower/less detailed way as compared to asserted and focalized parts of utterances. In other words, behavioral experiments confirm that introducing some information as already shared by addressees reduces their epistemic vigilance.

2. During and after the processing of an utterance, recognizing what is false in it requires more time, i.e., more processing effort, if the false content is encoded by means of a construction that takes it for granted (presupposition or topic), and less time/effort if it is encoded via direct assertion. This confirms that the false component of some information more probably settles in addressees' representations of the world when it is presented as already in their possession (i.e., as a presupposition or a topic) as compared to when it is presented as a contributon of the source (i.e., asserted).

Recently, scholars have tried to verify these assumptions by collecting neurophysiological evidence. But the experiments aimed at finding lesser processing effort associated to presuppositions and topics have produced slightly puzzling results. We will try to account for this in section Counter-Evidence From Neurophysiological Experiments.
TABLE 2 | Stimuli from Masia et al. (2017).

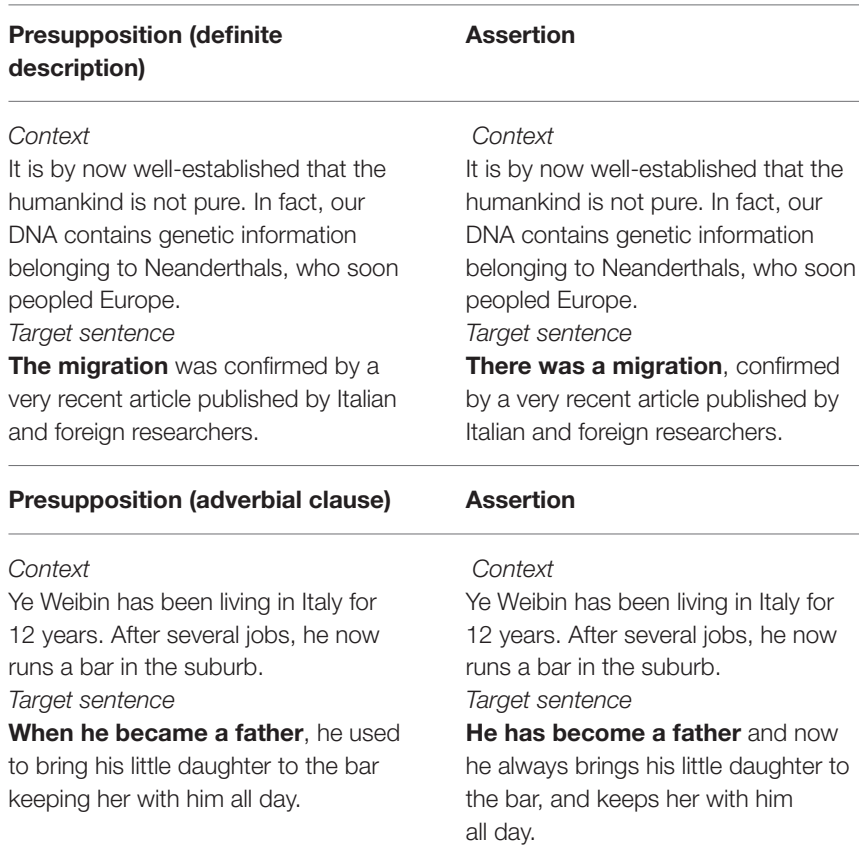

\section{Counter-Evidence From Neurophysiological Experiments}

The question is: does the different epistemic vigilance associated to presuppositions and topics as compared to assertion and focus result in measurable evidence regarding brain activity? ${ }^{10}$

Works like Burkhardt and Roehm (2007) have found an N400 effect associated to the processing of New vs. Given information in linguistic utterances. This can be seen as evidence that the updating function, i.e., the introduction of new contents into memory, requires additional energy as compared to just linking some content to its already existing representation in memory. But what happens when the content is the same, and only its linguistic presentation varies? Shouldn't some effect be measured for assertion as compared to the presupposition of the same content?

An EEG experiment we conducted recently (Masia et al., 2017) tried to answer this question. Subjects processed linguistic contexts ending with an utterance which either asserted or presupposed the same information (in bold type in Table 2), not previously introduced by the context. If the presupposition induced less effort, that should have been revealed in subjects' brain activity. Stimuli (originally, in Italian) were like those in Table 2.

However, the experiment revealed an N400 effect for presupposition, which means additional effort as compared to assertion.

This can be explained by the fact that the information encoded by both constructions was actually new in the context. Unfortunately, contexts where the target information

\footnotetext{
${ }^{10}$ Studies shedding some light on the matter are summarized more extensively than
} we can do here in Masia (2017), sections 4.3.4 and 4.3.5. 
has been previously introduced cannot be used in such an experiment, because, contrary to new/unknown information, which can be encoded both by assertion and by accommodated presupposition, active/known information can obviously be re-introduced by presupposition, but its re-introduction by assertion results in strong awkwardness. Now, as a result of the information being new, the presupposition was not satisfied, but had to be accommodated (Lewis, 1979). It can be hypothesized that, at first, information presented as presupposed induced addressees to look for it in their memory and to make a linking with what they already knew. But when that information turned out to be unknown, addressees were obliged to give up this strategy, and adopt another; namely, to update their register with that information.

This double movement (error and correction), which in that study we have proposed to call a pragmatic garden path, must have cognitive costs. Our hypothesis is that the N400 effect associated to presupposition measured the additional effort of accommodation, i.e., the need to remedy the mismatch between the actual cognitive status of some information (i.e., unknown) and the way it was linguistically packaged. This result can be compared to what is accounted for in Jouravlev et al. (2016), where, with presuppositions triggered by again, a P600 effect was associated to accommodation (i.e., when the presupposition's content had not been previously introduced) as compared to satisfaction (when the content had been previously introduced). Our and Jouravlev's results are similar, because they reveal that accommodation is costly, but they are not identical: both because one involved N400 and the other P600 effects, and because in our experiment the compared conditions were presupposition vs. assertion, while in Jouravlev's they were accommodated vs. satisfied presupposition.

In a subsequent EEG experiment (Domaneschi et al., 2018) we confirmed Jouravlev's results, because presuppositions to be accommodated, as compared to satisfied presuppositions, produced an $\mathrm{N} 400$ and a $\mathrm{P} 600$ effect, the latter probably to be interpreted as the effect of updating the register with new information as compared to just linking the utterance's content to information already present in the register. Similar to this, Hertrich et al. (2015) by using magnetoencephalography found an effect of greater cognitive effort when subjects processed definite descriptions presupposing the existence of contextually new referents, as compared to definite descriptions with previously introduced referents.

In La Rocca et al. (2016) we tested the same patterns with topic and focus, by measuring rhythmic activity in different frequency bands, especially $\theta, \alpha$ and $\beta$. Different subjects listened to different versions of linguistic contexts that were manipulated in order to have the same information (sometimes new, sometimes given in context), respectively in topic or in focus. Desynchronization in $\alpha$ and $\beta$ bands, as well as synchronization in $\theta$ band, showed that subjects made more effort for new topics as compared to given topics, and for given focuses as compared to new focuses. In other words, also for topic and focus EEG measurements revealed an effort devoted to coping with the mismatch between the contextual cognitive status of a content and its linguistic presentation.
This kind of experiments seem to confirm, in general, one thing: that presupposition (and topic) is costlier when its referent has not been previously introduced. In particular, this means that encoding new, unknown information as if it is already shared imposes an "accommodation cost" related to the mismatch between linguistic packaging of some content and its actual informational status in the ongoing discourse. Presupposition or topicalization of new information that needs accommodation have higher processing costs not only as compared to satisfied presupposition/topicalization of already shared content (which is expected), but also, much less obviously, as compared to plain assertion of new content.

This did not match our expectations, based on behavioral experiments, of less processing effort for presupposition and topic as compared to assertion and focus.

\section{INTERPRETING DISORDER: WE DON'T MEASURE THE RIGHT THING YET}

The present state of our knowledge on the processing of presuppositions and topics looks like a dialogue between disagreeing persons. The way implicit responsibility is exploited in advertising and propaganda seems to tell us: "Presuppositions and topics are effective in persuasion and manipulation because they induce less attentive processing, which can ease acceptation of questionable contents." Behavioral evidence seems to reinforce the message: "Yes, indeed: we have proof (different accuracy, different processing times) that presuppositions and topics reduce critical attention, causing faster and shallower processing."

Still, neurophysiological evidence disagrees: "No, on the contrary! The only thing we seem to know is that if some content is not already shared by the addressee, its being encoded as presupposed or as a topic causes additional effort (as compared to directly asserting it). We have found no trace of lesser effort with presuppositions and topics as compared to focal assertions."

The dispute can be settled, at least on a theoretical level. If presuppositions and topics cause lesser attention but give rise to greater measured processing effort, this can mean that the effort we have measured so far with accommodated presuppositions and topics is not the effort devoted to critical evaluation of their content, but something else. Actually, what is presented as already known comes with the instruction to retrieve it in one's previous knowledge, but ends up being nowhere to be found. So, the misled addressee has to give up the linking to previous knowledge and must undertake a second strategy: the updating of the register with new information. Consequently, the mismatch between the status of some content in memory and its linguistic presentation is likely to cause additional processing effort.

Not only is this effort not devoted to critical evaluation: it is even likely to hinder it. In fact, as every effort does, it drains attentional resources, subtracting them from concurrent epistemic vigilance, which is also reduced by the impression that the presupposed content is already shared and granted. Moreover, in presence of the already mentioned "Now-or-Never Bottleneck," if a content is presented as not needing careful 
evaluation because it is already shared, and during its processing there is a leak of attentional resources due to the necessity to deal with the mentioned accommodation mismatch, very few resources remain to exercise vigilance. In other words, the additional effort required by presupposition accommodation distracts from critical evaluation, which is already discouraged by presentation of that content as known and granted. These combined effects may explain very well why implicitness of responsibility is so effective in smuggling disputable contents into the target's minds.

From a neurophysiological point of view, if this hypothesis is true we should draw the following conclusion: what we have been measuring so far with EEG techniques is not the cost of critical evaluation. The ERPs we have found correspond to more primary functions of the processing of linguistic contents. The brain correlates of epistemic vigilance are still to be found. Actually, this is a fascinating research path, that still has to be almost completely charted.

\section{REFERENCES}

Aikhenvald, A. (2004). Evidentiality. Oxford: Oxford University Press.

Allott, N., and Rubio Fernández, P. (2002). "This paper fills a much-needed gap," in Actes de l?Atelier des doctorants en linguistique, 97-102.

Barsalou, L. (1992). Cognitive Psychology: An Overview for Cognitive Scientists. New York, NY: Lawrence Erlbaum Associates.

Birch, S., and Rayner, K. (1997). Linguistic focus affects eye movements during reading. Memory Cogn. 25, 653-660. doi: 10.3758/BF03211306

Bredart, S., and Modolo, K. (1988). Moses strikes again: focalization effect on a semantic illusion. Acta Psychol. 67, 135-144. doi: 10.1016/0001-6918(88)90009-1

Burkhardt, P., and Roehm, D. (2007). Differential effects of saliency: an event-related brain potential study. Neurosci. Lett. 413, 115-120. doi: 10.1016/j.neulet.2006.11.038

Chafe, W. J. (1987). "Cognitive constraints on information flow," in Coherence and Grounding in Discourse, ed. R.S. Tomlin (Amsterdam; Philadelphia, PA: Benjamins), 21-51. doi: 10.1075/tsl.11.03cha

Chafe, W. J. (1992). "Information flow in speaking and writing," in The Linguistics of Literacy, eds. P. Downing, S. D. Lima, and M. Noonan (Amsterdam; Philadelphia, PA: Benjamins), 17-29. doi: 10.1075/tsl.21.05cha

Christiansen, M., and Chater, N. (2016). The now-or-never bottleneck: a fundamental constraint on language. Behav. Brain Sci. 39, 1-19. doi: $10.1017 /$ S0140525X1500031X

Cresti, E. (2000). Corpus di italiano parlato. Firenze: Accademia della Crusca.

De Saussure, L. (2013). Background relevance. J. Pragmatics 59, 178-189. doi: 10.1016/j.pragma.2013.08.009

De Saussure, L. (2014). "Présuppositions discursives, assertion d'arrière-plan et persuasion," in Rhétorique et cognition - Perspectives théoriques et stratégies persuasives, eds. Th. Herman, and S. Oswald (Pieterlen: Peter Lang), 279-311.

De Saussure, L., and Oswald, S. (2009). Argumentation et engagement du locuteur. Pour un point de vue subjectiviste. Nouveaux cahiers de linguistique française $29,215-243$.

Domaneschi, F., Canal, P., Masia, V., Lombardi Vallauri, E., and Bambini, V. (2018). N400 and P600 modulation in presupposition accommodation: the effect of different trigger types. J. Neurolinguistics 45, 13-35. doi: 10.1016/j.jneuroling.2017.08.002

Ducrot, O. (1972). Dire et ne pas dire. Paris: Hermann.

Erickson, T. D., and Mattson, M. E. (1981). From words to meanings: a semantic illusion. J. Verbal Learn. Verbal Behav. 205, 540-551. doi: 10.1016/S0022-5371(81)90165-1

Ferreira, F., Bailey, K. G. D., and Ferraro, V. (2002). Good-enough representations in language comprehension. Curr. Dir. Psychol. Sci. 11, 11-15. doi: $10.1111 / 1467-8721.00158$

\section{DATA AVAILABILITY STATEMENT}

The original contributions presented in the study are included in the article/supplementary material, further inquiries can be directed to the corresponding author.

\section{AUTHOR CONTRIBUTIONS}

The author confirms being the sole contributor of this work and has approved it for publication.

\section{FUNDING}

This paper has been funded by the Italian Ministry for University and Research (MIUR) through the project IMPAQTS: Implicit Manipulation in Politics-Quantitatively Assessing the Tendentiousness of Speeches (PRIN: Research Project of National Interest 2017, grant no. 2017STJCE9: www.impaqts.it).

Gigerenzer, G. (2008). Why heuristics work. Persp. Psychol. Sci. 3, 20-29. doi: 10.1111/j.1745-6916.2008.00058.x

Givón, T. (1982). Evidentiality and epistemic space. Stud. Lang. 61, 23-49. doi: 10.1075/sl.6.1.03giv

Gould, S. J., and Vrba, E. S. (1982). Exaptation - a missing term in the science of form. Paleobiology 8, 4-15. doi: 10.1017/S0094837300004310

Hertrich, I., Kirsten, M., Tiemann, S., Beck, S., Wühle, A., Ackermann, H., et al. (2015). Context-dependent impact of presuppositions on early magnetic brain responses during speech perception. Brain Lang. 148, 1-12. doi: 10.1016/j.bandl.2015.06.005

Hornby, P. A. (1974). Surface structure and presupposition. J. Verbal Learn. Verbal Behav. 13, 530-538. doi: 10.1016/S0022-5371(74)80005-8

Irwin, D. E., Bock, K. J., and Stanovich, K. E. (1982). Effects of information structure cues on visual word processing. J. Verbal Learn. Verbal Behav. 21, 307-325. doi: 10.1016/S0022-5371(82)90637-5

Jouravlev, O., Stearns, L., Bergen, L., Eddy, M., Gibson, E., and Fedorenko, E. (2016). Processing temporal presuppositions: an event-related potential study. Lang. Cogn. Neurosci. 31, 1245-1256. doi: 10.1080/23273798.2016.1209531

Kamas, E. N., Reder, L. M., and Ayers, M. S. (1996). Partial matching in the moses illusion: response bias not sensitivity. Memory Cogn. 24, 687-699. doi: 10.3758/BF03201094

Kerbrat-Orecchioni, C. (1986). L'Implicite. Paris: Armand Colin.

Krebs, J. R., and Dawkins, R. (1984). "Animal signals: mind-reading and manipulation," in Behavioral Ecology: An Evolutionary Approach, eds. J. R. Krebs, and N. B. Davies (Sunderland, MA: Sinauer Associates), 380-402.

La Rocca, D., Masia, V., Maiorana, E., Lombardi Vallauri, E., and Campisi, P. (2016). Brain response to information structure misalignments in linguistic contexts. Neurocomputing 199, 1-15. doi: 10.1016/j.neucom.2016.03.001

Langford, J., and Holmes, V. M. (1979). Syntactic presupposition in sentence comprehension. Cognition 7, 363-383 doi: 10.1016/0010-0277(79)90022-2

Lewis, D. (1979). Scorekeeping in a language game. J. Philos. Logic 8, 339-359. doi: $10.1007 /$ BF00258436

Loftus, E. F. (1975). Leading questions and the eyewitness report. Cogn. Psychol. 7, 550-572. doi: 10.1016/0010-0285(75)90023-7

Lombardi Vallauri, E. (1993). Clausole a contenuto presupposto e loro funzione discorsiva in italiano antico. Quaderni del dipartimento di Linguistica dell'Università di Firenze 4, 71-95.

Lombardi Vallauri, E. (1995). Tratti linguistici della persuasione in pubblicità. Lingua Nostra 2, 41-51.

Lombardi Vallauri, E. (2009a). "Grice elettorale," in Linguistica e Società. Studi in onore di Franca Orletti, eds. M. Fatigante, L. Mariottini, and E. Sciubba (Milano: Franco Angeli), 172-184.

Lombardi Vallauri, E. (2009b). La struttura informativa. Forma e funzione negli enunciati linguistici. Roma: Carocci. 
Lombardi Vallauri, E. (2016). The "exaptation" of linguistic implicit strategies. SpringerPlus 5, 1-24. doi: 10.1186/s40064-016-2788-y

Lombardi Vallauri, E. (2019). La lingua disonesta. Bologna: Il Mulino.

Lombardi Vallauri, E., Baranzini, L., Cimmino, D., Cominetti, F., Coppola, C., and Mannaioli, G. (2020). Implicit argumentation and persuasion. J. Argumentation Context 9, 95-123 doi: 10.1075/jaic.00009.lom

Lombardi Vallauri, E., and Masia, V. (2014). Implicitness impact: measuring texts. J. Pragmatics 61, 161-184. doi: 10.1016/j.pragma.2013.09.010

Lombardi Vallauri, E., and Masia, V. (2015). "Cognitive constraints on the emergence of topic-focus structure in human communication," in Immagine e pensiero. Bilanci nelle scienze cognitive attuali, eds. A. Chiera, and V. Ganfi (Roma; Messina: Corisco), 180-204.

Lombardi Vallauri, E., and Masia, V. (2020). "La comunicazione implicita come dimensione di variazione tra tipi testuali," in Linguaggi settoriali e specialistici. Sincronia, diacronia, traduzione, variazione, eds. J. Visconti, M. Manfredini, and L. Coveri (Firenze: Cesati), 113-120.

Maillat, D., and Oswald, S. (2009). Defining manipulative discourse: the pragmatics of cognitive illusions. Int. Rev. Pragmatics 1, 348-370. doi: 10.1163/187730909X12535267111651

Masia, V. (2017). Sociobiological bases of information structure. Amsterdam; Philadelphia, PA: Benjamins. doi: 10.1075/ais.9

Masia, V., Canal, P., Ricci, I., Lombardi Vallauri, E., and Bambini, B. (2017). Presupposition of new information as a pragmatic garden path: evidence from event-related brain potentials. J. Neurolinguistics 42, 31-48. doi: 10.1016/j.jneuroling.2016.11.005

Mazzarella, D., Reinecke, R., Noveck, I., and Mercier, H. (2018). Saying, presupposing and implicating: how pragmatics modulates commitment. $J$. Pragmatics 133, 15-27. doi: 10.1016/j.pragma.2018.05.009

Mercier, H. (2009). La Théorie Argumentative du Raisonnement (Ph.D. thesis in Social Sciences, Mention Cognitive Sciences). E.H.E. S.S, Paris.

Miller, G. A. (1956). The magical number seven, plus or minus two: some limits of our capacity for processing information. The Psychological Review 63, 81-97.

Oswald, S., Maillat, D., and de Saussure, L. (2016). "Deceptive and uncooperative verbal communication," in Verbal Communication Handbooks of Communicative Science 3, eds. L. de Saussure, and A. Rocci (Berlin: Walter de Gruyter), 509-534.

Reboul, A. (2011). A relevance-theoretic account of the evolution of implicit communication. Stud. Pragmatics 13, 1-19.

Reboul, A. (2017). Cognition and communication in the evolution of language. Oxford; New York, NY: Oxford University Press. doi: 10.1093/acprof:oso/9780198747314.001.0001
Rigotti, E. (1988). "Significato e senso," in Ricerche di semantica testuale (Brescia: La Scuola), 71-120.

Sanford, A. J. (2002). Context, attention and depth of processing during interpretation. Mind Lang. 17, 188-206. doi: 10.1111/1468-0017.00195

Sbisà, M. (2007). Detto non detto. Le forme della comunicazione implicita. RomaBari: Laterza.

Schwarz, F. (2015). "Presuppositions vs. asserted content in online processing," in Experimental Perspectives on Presupposition. Studies in Theoretical Psycholinguistics, ed. F. Schwarz (Dordrecht: Springer), 89-108. doi: 10.1007/978-3-319-07980-6_4

Schwarz, F. (2016). False but slow: evaluating statements with non-referring definites. J. Semantics 33, 177-214. doi: 10.1093/jos/ffu019

Schwarz, F., and Tiemann, S. (2017). Presupposition projection in online processing. J. Semantics 34, 61-106. doi: 10.1093/jos/ffw005

Sperber, D., Cara, F., and Girotto, V. (1995). Relevance theory explains the selection task. Cognition 57, 31-95. doi: 10.1016/0010-0277(95)00666-M

Sperber, D., Clément, F., Heintz, C.h., Mascaro, O., Mercier, H., Origgi, G., et al. (2010). Epistemic vigilance. Mind Lang. 25-4, 359-393. doi: 10.1111/j.1468-0017.2010.01394.x

Stalnaker, R. (2002). Common ground. Linguist. Philos. 25, 701-721. doi: 10.1023/A:1020867916902

Strawson, P. F. (1964). "Identifying reference and truth-values," in Theoria 302, 96-118. Republished in Strawson, P.F. (1971). Logico-Linguistic Papers. London: Methuen, 75-95.

Sturt, P., Sandford, A. J., Stewart, A., and Dawydiak, E. (2004). Linguistic focus and good-enough representations: an application of the changedetection paradigm. Psychon. Bull. Rev. 11, 882-888. doi: 10.3758/BF03 196716

Tversky, A., and Kahneman, D. (1974). Judgment under uncertainty: heuristics and biases. Science 185, 1124-1131. doi: 10.1126/science.185.4157. 1124

Conflict of Interest: The author declares that the research was conducted in the absence of any commercial or financial relationships that could be construed as a potential conflict of interest.

Copyright $\odot 2021$ Lombardi Vallauri. This is an open-access article distributed under the terms of the Creative Commons Attribution License (CC BY). The use, distribution or reproduction in other forums is permitted, provided the original author(s) and the copyright owner(s) are credited and that the original publication in this journal is cited, in accordance with accepted academic practice. No use, distribution or reproduction is permitted which does not comply with these terms. 